\title{
El estado de la ciencia durante el COVID-19 y el derecho al consentimiento informado
}

\author{
O estado da ciência durante o COVID-19 e o direito ao consentimento informado
}

The state of science during COVID-19 and the right to informed consent

\author{
Manuel Ortiz Fernández*
}

\section{Resumen}

La situación generada por el COVID-19 (SARS-CoV-2) nos obliga a repensar el sistema de responsabilidad civil sanitario $\mathrm{y}$, dentro del mismo, el aplicable al ámbito del consentimiento informado. En este sentido, para determinar la adecuación de la conducta a la lex artis ad hoc se hace necesario reflexionar acerca del estado de la ciencia para determinar si los conocimientos permitían actuar en otro sentido. Desde nuestra perspectiva, no cabe reprochar aquellos actos que, no siendo los idóneos desde una perspectiva ex post, aparecían como los correctos con el conocimiento que se manejaba cuando se llevaron a cabo (ex ante). Pues bien, en principio, existen argumentos suficientes para afirmar que no contamos, en la actualidad, con datos suficientes sobre el origen, las consecuencias y las características esenciales del virus y que, por tanto, no nos encontramos en un estadio de total dominio por parte de la comunidad científica. Este motivo provoca que podamos aplicar una moderación o limitación de responsabilidad sobre ciertos actos e, incluso, una ausencia de la misma.

Palabras clave: Consentimiento informado. COVID-19. Estado de la ciencia. Lex artis. Negligencia.

\section{Resumo}

A situação gerada pelo novo coronavírus (SARS-CoV-2) exige que repensemos o sistema de responsabilidade sanitária e, dentro dele, o aplicável ao campo do consentimento informado. Nesse sentido, para determinar a adequação da conduta ao lex artis ad hoc é necessário refletir sobre o estado da ciência, a fim de determinar se o conhecimento permitiu agir em uma direção diferente. Do nosso ponto de vista, não é possível culpar esses atos que, não sendo adequados a partir de uma perspectiva ex post, apareceram como certos com o conhecimento que havia quando foram realizados (ex ante). Em princípio, há argumentos suficientes para afirmar que, atualmente, não temos dados suficientes sobre a origem, as consequências e as características essenciais do vírus e que, portanto, não estamos em um estágio de total domínio por parte da comunidade científica. Essa razão nos faz aplicar uma moderação ou limitação de responsabilidade a determinados atos e, até mesmo, a sua ausência.

Palavras-chave: Consentimento informado. COVID-19. Estado da ciência. Lex artis. Negligência.

\section{Abstract}

The situation generated by COVID-19 (SARS-CoV-2) requires us to rethorder the health liability system and, within it, that applicable to the scope of informed consent. In this sense, in order to determine the adequacy of the behavior to the lex artis ad hoc it is necessary to reflect on the state of science in order to determine whether knowledge allowed to act in another direction. From our perspective, it is not possible to reproach those acts that, not being suitable from an ex post perspective, appeared as the right ones with the knowledge that was handled when they were carried out (ex ante). In principle, there are sufficient arguments to state that we do not currently have sufficient data on the origin, consequences and essential characteristics of the virus and that we are therefore not in a stage of total dominance on the part of the scientific community. This reason causes us to apply a moderation or limitation of liability for certain acts and even an absence thereof.

Keywords: Informed Consent. COVID-19. State of Science. Lex artis. Negligence. 


\section{Introducción}

Como es sabido, el surgimiento del COVID-19 (SARS-CoV-2) y su propagación ha producido unas consecuencias nefastas en diversos ámbitos. ${ }^{1}$ Sin duda, el efecto más grave es el elevado número de fallecimientos que ha producido que, en la actualidad, supera los novecientos sesenta y cinco mil. A ello hay que anudar que la cifra de casos confirmados es de más de treinta millones. Asimismo, el sector económico de las distintas naciones también se ha visto duramente resentido por el descenso de la actividad. En este sentido, muchos estados tuvieron que decretar estados de emergencia cuya medida fundamental residió en la restricción de la libertad deambulatoria. En la mayoría de los casos, se ha recobrado la "nueva normalidad" pero la aparición de rebrotes está obligando a que se aprueben, de nuevo, limitaciones a los derechos y las libertades de los ciudadanos con el fin de detener los nuevos contagios.

En España, el 14 de marzo se estableció el estado de alarma y el confinamiento de la población. El día 21 de junio finalizó el mismo y se inició un plan de desescalada donde se previó la salida progresiva de este contexto (en cuatro fases). No obstante, como se ha señalado, se están comenzando a vislumbrar nuevos rebrotes de coronavirus, lo que está conllevando la imposición de alguna medida complementaria para paliarlo. Lejos de finalizar, parece que este escenario se mantendrá en un tiempo todavía prolongado.

Como rápidamente se comprenderá, este escenario repercute, inexorablemente, en el sistema de responsabilidad civil. Así, las especiales circunstancias en las que nos encontramos pueden justificar que recurramos a la aplicación de mecanismos (ORTIZ FERNÁNDEZ, 2020, p. 298-302) que, de algún modo, rebajen el nivel de exigencia de las prestaciones acordadas (en el sector contractual) o que excepcionen la reparación del daño causado (en sede extracontractual). Además, el ámbito sanitario no es ajeno a tal eventualidad. Muy al contrario, se trata de uno de los campos más afectados por el COVID-19 en tanto en cuanto se ha visto forzado a tratar, de forma directa, con el citado virus. En este marco, la adecuada prestación del consentimiento informado y el cumplimiento de los deberes impuestos por nuestra legislación también se ha mermado, ya que el propio desconocimiento acerca del coronavirus ha impedido que los sanitarios puedan informar correctamente.

Ante este panorama, se hace necesario que reflexionemos acerca de la situación generada por el COVID-19 y de las consecuencias que se han derivado para tratar de determinar si, en este caso, el estado de la ciencia permitía advertir estos extremos. Sea como fuere, debe tenerse en cuenta que estamos ante una cuestión muy compleja y que no se encuentra exenta de discusión. Muy al contrario, en este trabajo vamos a tratar de esbozar y manifestar nuestra particular interpretación, pero entendemos que pueden esgrimirse argumentos adecuados en un sentido diferente. Asimismo, por las propias peculiaridades del contexto, no cabe extraer verdades generales aplicables a otros ámbitos y es necesario estudiar caso por caso.

En otro orden de cosas, conviene tener en cuenta que en España la materia referida a la sanidad es compartida entre Estado y comunidades autónomas. Por este motivo, un estudio completo obligaría a analizar todas las normativas autonómicas, cuestión que excede de la finalidad de esta obra. Baste con señalar que muchas de las políticas legislativas sectoriales no son todo lo adecuadas que sería deseable. En este sentido, al emprender esta tarea, algunos territorios han aprobado disposiciones que no respetan el orden constitucional y contradicen la legislación básica nacional. Por su parte, en otras comunidades las normas son excesivamente escuetas y se limitan a reiterar los mandatos de la Ley 41/2002. No obstante, consideramos que ciertos aspectos que se contemplan en las leyes autonómicas complementan y enriquecen a la norma estatal y resultan de vital importancia para el respeto de los derechos de los pacientes. A modo de ejemplo, se prevé el plazo mínimo que debe transcurrir entre la firma del documento de consentimiento informado y la ejecución de la intervención de que se trate, lo que, sin duda, contribuye a una mejor comprensión por parte del usuario de todos los aspectos vinculados a la operación y a que, en definitiva, pueda decidir libre $y$ voluntariamente.

No cabe, pues, asimilar esta situación, por razones obvias, a las producidas por otras enfermedades como la gripe. Puede consultarse el Anexo - X sobre la vigilancia de la gripe en el transcurso de una pandemia. fases 4, 5 y 6 de la OMS en: https://www.mscbs.gob.es/ciudadanos/enfLesiones/ enfTransmisibles/docs/anexoX_Septiembre2006.pdf. Fecha de última consulta: 05 Mayo 2020. 


\section{El consentimiento informado como derecho de todo paciente: implicaciones y naturaleza jurídica}

En primer lugar, conviene señalar que el reconocimiento del consentimiento informado se ha producido de forma paulatina. En este sentido, ha sido necesario que evolucionen los presupuestos clásicos de la relación médico-paciente (modelo paternalista clásico) para que los usuarios de los centros sanitarios dispongan de derechos en este ámbito (etapa de decisiones compartida entre médico y paciente), esto es, para que puedan decidir en el campo sanitario. En suma, supone una manifestación del derecho de autodeterminación, en la medida en que permite que el paciente pueda escoger entre las opciones clínicas posibles. Como destaca de una forma muy acertada Barceló Doménech (2018, p. 281), "El fundamento del consentimiento informado está en la idea de autonomía individual del paciente y el estímulo a la toma de decisiones racionales. Se trata de decidir con el paciente y no por él desde la superioridad del criterio médico".

En palabras de la Ley 41/2002, de 14 de noviembre, básica reguladora de la autonomía del paciente y de derechos y obligaciones en materia de información y documentación clínica (en adelante, Ley 41/2002), aparece como "la conformidad libre, voluntaria y consciente de un paciente, manifestada en el pleno uso de sus facultades después de recibir la información adecuada, para que tenga lugar una actuación que afecta a su salud" (art. 3).

Como se observa, se encuentra formado por dos facultades íntimamente vinculadas: información previa y posterior consentimiento. No puede perderse de vista que no se podrá decidir de forma libre, consciente y voluntaria sin contar con todos aquellos datos y aspectos relevantes de la intervención de que se trate. Por ello, por más que se preste el consentimiento en estas circunstancias, el mismo únicamente tendrá un carácter formal y no conllevará el cumplimiento de los imperativos legales.

No obstante, no puede pensarse que estamos ante un derecho absoluto (en realidad, ninguno lo es). Muy al contrario, la Ley 41/2002 recoge una serie de limites al mismo. Así, las especiales circunstancias que rodean al supuesto pueden provocar que, en el caso concreto, nos encontremos ante una excepción. En tales supuestos, o bien el médico o bien los familiares tendrán que actuar en representación y beneficio del usuario, sustituyendo su voluntad.

En cuanto a su naturaleza jurídica, se han planteado varias interpretaciones posibles. Por un lado, se presenta la dicotomía entre si estamos ante un mero derecho de configuración legal o si, por el contrario, se trata de un derecho fundamental (no recogido en nuestra Constitución). Esta última postura ha sido acogida por el Tribunal Supremo en algunas sentencias, ${ }^{2}$ en las que ha afirmado que

[...] constituye un derecho humano fundamental, precisamente una de las últimas aportaciones realizada en la teoría de los derechos humanos, consecuencia necesaria o explicación de los clásicos derechos a la vida, a la integridad física y a la libertad de conciencia. Derecho a la libertad personal, a decidir por sí mismo en lo atinente a la propia persona y a la propia vida y consecuencia de la autodisposición sobre el propio cuerpo.

Desde nuestra perspectiva, esta opción no es acertada, ya que nuestra legislación, en ningún punto, atribuye esta cualidad al consentimiento. ${ }^{3}$

\footnotetext{
Entre otras, vid. las SSTS n. 3/2001 12 enero 2001 (RJ 3), n. 447/2001 11 mayo 2001 (RJ 6197).

En este sentido, la propia Ley 41/2002 parece inclinarse por esta postura al señalar en su disposición adicional primera que "Esta Ley tiene la condición de básica, de conformidad con lo establecido en el artículo 149.1.1. a y 16. a de la Constitución". Si se observa, el primero de los artículos, al referirse a las competencias exclusivas del Estado, habla de "regulación de las condiciones básicas que garanticen la igualdad de todos los españoles en el ejercicio de los derechos y en el cumplimiento de los deberes constitucionales". Así, el consentimiento informado se configura como una garantía de igualdad en el ejercicio de su derecho fundamental (constitucional) a la integridad física y moral.

A mayor abundamiento, otra cuestión que refuerza nuestro posicionamiento es que los derechos fundamentales aparecen como indisponibles para los ciudadanos, esto es, que no cabe renunciar a los mismos. Sin embargo, la Ley 41/2002 formula el consentimiento informado como un derecho disponible por los pacientes. Así lo demuestra el artículo 4.1 de la citada ley al señalar que "toda persona tiene derecho a que se respete su voluntad de no ser informada", a pesar de que, más tarde, la citada norma limita este extremo. De alguna forma, se desprende de la norma que el derecho a la información es disponible, con ciertas limitaciones y que, el consentimiento, en todo caso, tendrá que ejercitarse. Es decir, que ya sea en un sentido u otro -decidir intervenirse o no-, el paciente tendrá que manifestarse siempre. Entendemos que el legislador es consciente de la relevancia de este derecho, pues representa una garantía de un derecho fundamental y, por ello, trata de "blindarlo". De este modo, busca evitar que se den situaciones en que el profesional intervenga a un paciente sin su consentimiento fuera de los casos expresamente previstos.
} 
Tras ello y una vez descartada la anterior correspondencia, parece razonable pensar que nos encontramos ante un mero derecho de configuración legal. Máxime si atendemos al propio carácter ordinario de la ley reguladora del mismo. No obstante, entendemos que esta conclusión tampoco es apropiada y ninguna de las dos posiciones representa la naturaleza del consentimiento informado. A nuestro parecer, ha de optarse por una tercera posibilidad, a saber, categorizar el consentimiento como un derecho de configuración legal, pero con implicaciones constitucionales. De esta forma, sostenemos que la vulneración del consentimiento puede llevar aparejada la conculcación de otros derechos recogidos en la Constitución Española, apareciendo el primero como una realidad diferente y separada de los segundos. Desde esta perspectiva, algunos autores ponen de relieve que algunos de los contenidos e instituciones típicamente civiles han pasado a alcanzar rango constitucional, como la protección de los consumidores y usuarios o de los menores (GUTIÉRREZ SANTIAGO, 2011, p. 51-86).

Esta postura es la más adecuada, ya que representa una interpretación acorde con nuestro ordenamiento jurídico y doctrina constitucional. En este sentido, algo parecido se puede extraer de las conclusiones que adoptan algunos autores cuando ponen de relieve que el consentimiento informado: "es más bien un principio que garantiza los derechos fundamentales del paciente en sus relaciones con la sanidad, que afecta, no obstante, a su esfera más íntima, a sus más elementales derechos”. (SARDINERO GARCÍA, 2016, p. 43).

Así, parte de la doctrina sitúa el consentimiento informado como "un instituto con relevancia constitucional", esto es:

[...] un instrumento, un procedimiento creado para asegurar los derechos fundamentales del paciente, haciendo que quede constancia cierta, no sólo del conocimiento y de la aceptación de un tratamiento que afecta a su esfera más íntima, a sus más elementales derechos, sino también a su libertad de elección, por eso el consentimiento informado debiera estar protegido como si fuera un derecho fundamental. (BLANCO PÉREZ-RUBIO, 2014, p. 96-97; ROVIRA VIÑAS, 2006, p. 7-54).

No obstante, el consentimiento informado no se agota aquí. Muy al contrario, además de aparecer como una garantía (o un instrumento) al servicio de los derechos fundamentales, representa una facultad autónoma digna de protección (En contra, ROVIRA VIÑAS, 2007, p. 109). Estamos ante una serie de cuestiones muy relevantes para los particulares y su vulneración debe ir acompañada de responsabilidad. En suma, se trata de un derecho de configuración legal y, por tanto, con un espacio concreto de protección que, además, supone una garantía de un derecho fundamental.

Desde esta perspectiva, no parece que la vía constitucional quede expedita en cualquier caso, sino únicamente cuando los tribunales ordinarios obvien la inexistencia de información y el consentimiento, sin motivar su decisión de acuerdo con los parámetros legales. Ello no quiere decir que se excluya el consentimiento informado del ámbito de la constitucionalidad y que deba quedar recluido en la legalidad ordinaria interpretada secundum constitutionem, sino que se debe modular el acceso al recurso de amparo en función del caso concreto (DÍAZ MARTíNEZ, 2011, p. 32-33).

Sin embargo, tampoco la cuestión referida a la vinculación del consentimiento informado con los derechos tampoco se encuentra exenta de discusión. En una primera aproximación, podría pensarse que la relación directa del mismo se encuentra en el artículo 43 CE referido al "derecho a la protección de la salud". Pues bien, a pesar de la posible conexión entre ambos, consideramos que este último está más referido a la facultad genérica de poder disfrutar de servicios médicos que a la correcta información y consentimiento que la ley refiere. No nos parece correcto relegar la protección del consentimiento informado (al menos únicamente) a este principio constitucional.

Asimismo, es posible invocar la dignidad (art. $10 \mathrm{CE}$ ), la prohibición de discriminación por razón de sexo (art. $14 \mathrm{CE}$ ) y los consiguientes derechos a la identidad sexual y a la vida privada, la libertad ideológica, religiosa y de culto (art. $16 \mathrm{CE}$ ) y la libertad deambulatoria (art. $17 \mathrm{CE}$ ). Piénsese, por ejemplo, en los casos en los que, a la medida sanitaria, se anuda un internamiento no voluntario (como ha ocurrido en ciertas situaciones con el COVID-19). En tales supuestos, la referida libertad deambulatoria puede resultar comprometida. Igualmente, en los contextos en los que existen convicciones religiosas que impiden ciertos tratamientos cabe alegar el artículo $16 \mathrm{CE}$. 
Sin negar lo cierto de las anteriores teorías, consideramos que la vinculación del consentimiento informado (o, al menos, la más directa o relevante) la hallamos en el derecho a la integridad física y moral recogido en el artículo 15 CE (GÓMEZ ABEJA, 2011, p. 275-306). De hecho, nuestra postura viene avalada por el propio Tribunal Constitucional, ya que en la STC n. 37/2011 28 marzo 2011 (RTC 37) destacó que "el consentimiento del paciente a cualquier intervención sobre su persona es algo inherente, entre otros, a su derecho fundamental a la integridad física, a la facultad que éste supone de impedir toda intervención no consentida sobre el propio cuerpo, que no puede verse limitada de manera injustificada como consecuencia de una situación de enfermedad". Como señala el Tribunal, si bien es posible que otros derechos fundamentales puedan resultar afectados, el consentimiento aparece como una facultad de autodeterminación que supone, en suma, el libre desarrollo de la personalidad.

De este modo, el fundamento de este derecho se encuentra en el derecho fundamental a la integridad física y moral. En este sentido:

Así ha sido considerado por nuestro Tribunal Constitucional -en sentencia de 28 de marzo de 2011que encuentra, como una intromisión ilegítima, una intervención sin el adecuado consentimiento informado. Desde nuestra perspectiva, el consentimiento informado hay que identificarlo como una garantía del citado derecho fundamental -sin que pueda confundirse con él-, de tal suerte que una vulneración del primero puede llevar aparejada (aunque no necesariamente) la conculcación del segundo. (ORTIZ FERNÁNDEZ, 2019, p. 380).

Por último, al adentrarnos en el tema relativo a la responsabilidad derivada de la vulneración del derecho al consentimiento informado interesa poner de relieve varias ideas. Así, al tratarse de una actividad profesional el criterio para determinar la adecuación de la actuación del médico viene determinado por la lex artis ad hoc. Sin embargo, entendemos que no debe confundirse este tipo de obligaciones con las derivadas de la propia ejecución de la operación. Desde esta perspectiva, la solución más correcta pasa por diferenciar dos tipos de lex artis. ${ }^{4}$ De una parte, la denominada lex artis tradicional, vinculada a la propia técnica empleada para mejorar la salud del paciente, esto es, la praxis ejecutada en la intervención de que se trate. De otra parte, la nova lex artis, relacionada con el cumplimiento de los deberes impuestos por la Ley $41 / 2002$, es decir, con el respeto a los derechos a ser informado y a consentir libremente. Por este motivo:

[...] el juicio valorativo de la conducta de los profesionales está formado por dos partes (o momentos). En primer lugar, hay que atender a los deberes de información y consentimiento, tratando de observar si el facultativo cumplió con ellos. En segundo lugar, debemos analizar la propia actividad sanitaria, para dirimir si se adecúa al estándar de actuación del oficio. Obviamente, en muchos casos es necesario conocer este segundo momento (cómo llevo a cabo la intervención el médico) para compararlo con la información y el consentimiento que se prestó. Esto es, para tratar de determinar si lo que en un principio se comunicó por el sanitario y que autorizó el paciente se corresponde con lo que finalmente llevó a cabo el primero. En otros supuestos, sin embargo, ello no será imprescindible, ya que es posible que la información sea, por ejemplo, incorrecta por un error del profesional. De este modo, podemos encontrarnos con escenarios en los que se haya producido una infracción de una de las lex artis únicamente o con otras en las que se hayan conculcado las dos (procediéndose a una acumulación de acciones). (ORTIZ FERNÁNDEZ, 2019, p. 562).

Una vez destacado lo anterior, debemos señalar que ambos contextos se encuentran estrechamente conectados con el estado de la ciencia. En suma, este último implica que no se podrá responsabilizar a ninguna persona por aquellos hechos realizados que, si bien en abstracto no serían los idóneos, no era posible conocer su carácter perjudicial. En este sentido, en ocasiones, en el ámbito sanitario se ha recurrido a medicamentos o a procedimientos que, en el momento de utilizarlos (ex ante), aparecían como la mejor opción para la salud de los pacientes. Sin embargo, a posteriori, se ha demostrado que no cumplían esta función y que, incluso, tenían el efecto contrario. De algún modo, aplicando las teorías relativas al caso fortuito y a la fuerza mayor, estaríamos ante una exención de responsabilidad pues estas circunstancias

4 Asimismo, nuestra jurisprudencia se ha mostrado favorable a esta cuestión al destacar que el incumplimiento del consentimiento informado genera un daño autónomo, sin que sea relevante a estos efectos que la actuación médica haya sido correcta. En este sentido, vid. SSTS n. $2558 / 1992$ 31 julio 1996 (RJ 6084), n. 8065/1995 Sala Tercera 4 abril 2000 (RJ 3258), n. 828/2003 8 septiembre 2003 (RJ 6065 ). 
no pudieron ser previstas o, de serlo, el daño era inevitable (RÊGO MONTEIRO FILHO, 2020, p. 19-36; ROSENVALD, 2020, p. 256).

\section{Estado de la ciencia y COVID-19}

Como hemos indicado, en el ámbito sanitario debemos diferenciar dos tipos de lex artis, ya que el consentimiento informado debe separarse de la propia ejecución de la intervención. En este sentido:

Bajo la amplia fórmula lex artis (leges artium, legis artis o reglas del arte, entre otra terminología) se engloba el contenido de la libre y diligente actuación profesional, esto es, abriga aquella serie de actitudes y conocimientos aplicables a su ejercicio cuya obtención y práctica conlleva que el profesional sea socialmente reconocido como tal. A pesar de que esta propia voz -profesional- constituye un noción metajurídica, con varias significaciones, arrancando del sentido gramatical de profesión y en su acepción eminentemente sociológica equivale a ostentar determinados conocimientos en una concreta materia que llevan aparejados una cualificación profesional (plasmada, a su vez, en una certificación o título), constituyendo lo más característico de las profesiones liberales -como es la médica- la autonomía o independencia en su ejercicio con sometimiento, como criterio rector, a esta denominada lex artis con carácter prácticamente exclusivo. Diversos han sido los conatos en orden a definir esta lex (identificada, por lo general, con aquella regla de la técnica de actuación de la profesión que se trate) la cual viene referida, en último término, a aquella esfera de autonomía profesional cuya regulación exclusivamente incumbe a sus miembros (reputados artífices o profesionales) que, a la postre, son los encargados de encarnar un modelo de conducta representado por las reglas 0 técnicas específicas de un concreto arte u oficio incumbiendo, por ende, el establecimiento de tal lex en Medicina a la propia profesión médica. Cabe mantener que las leges artium de cada profesión son aquéllas que gobiernan la actuación de los profesionales que consideremos, toda vez que el genérico modelo de conducta del buen padre de familia se caracteriza, precisamente, por la negación de todo conocimiento técnico, su naturaleza no profesional o especializada. (DE LAS HERAS, 2005, p. 17-19).

No obstante, para determinar el contenido de la misma resulta esencial concretar el estado de la ciencia del momento de producción del hecho que se pretende imputar. En esta línea, indica la doctrina que, desde un punto de vista social:

el estado de bienestar propio de las sociedades modernas ha generado una mayor preocupación de las personas por su salud y, en consecuencia, por la prestación de los servicios sanitarios. (...) El usuario de los servicios sanitarios, no solo demanda del facultativo unos cuidados adecuados y conformes según los medios y estado de la ciencia a fin de conseguir su curación, sino ser informado de forma completa y clara sobre los aspectos relativos a su estado de salud y la actuación que precisa. (SÁNCHEZ GÓMEZ, 2014, p. 99).

No puede obviarse que las obligaciones de los profesionales variarán en función de este último, ya que no es posible exigir una conducta que no podía preverse en el momento de producirse. En este sentido, si no se conocía la existencia del COVID-19 ni sus causas, efectos o procedimientos de curación, no parece adecuado que deba reprocharse la actividad de los médicos. Este razonamiento es aplicable para todos aquellos supuestos en los que, por el propio desconocimiento, se informó erróneamente a los pacientes acerca de la enfermedad. De hecho, ni siquiera en el momento de escribir estas líneas se han descubierto, con certeza, las consecuencias del virus ni la posible vacuna (BARCELÓ DOMÉNECH, 2020, p. 118-125) o medicamento.

Para aclarar estas cuestiones, podemos indagar en otras enfermedades que eran ignoradas en el momento de generar daños y a las que se aplicó un razonamiento similar, esto es, se trató de determinar si el estado de la ciencia permitía tener constancia de estos extremos. Por ejemplo, podemos traer a colación los contagios producidos por VHC (hepatitis C). A este respecto, la doctrina aludió a estas disquisiciones, señalando que:

la comunidad científica internacional conocía, desde 1975, la existencia de un virus causante de la hepatitis que no era ni A ni B, así como lo es que no fue hasta 1989 cuando pudo identificarse el virus de la hepatitis $\mathrm{C}(\mathrm{VHC}) \mathrm{y}$, por consiguiente, pudo desarrollarse el primer test de detección del virus en cuestión. También es cierto que en el Estado español, la obligación de analizar la presencia de VHC en las donaciones de sangre se impuso en octubre de 1990. (BLAS ORBÁN, 2008, p.181-182). 
Igualmente, la jurisprudencia se manifestó en estos términos. ${ }^{5}$ Por su parte, también la transmisión de $\mathrm{VIH}$ (virus de la inmunodeficiencia humana) planteó equivalentes problemáticas, sobre lo cual se indicó que "Los avances de la ciencia no han sido paralelos en cuanto a técnicas de control de hemoderivados y de transfusiones sanguíneas, por lo que su tratamiento debe hacerse por separado" (MUGA MUÑOZ, 1995, p. 287). El Tribunal Supremo ${ }^{6}$ destacó en diversas sentencias que "hasta el año 1985 el estado de los conocimientos de la técnica no permitía detectar la existencia de VIH en sangre", de tal suerte que "todas las transfusiones de plasma, efectuadas con anterioridad a dicho año 1985, en que se hubiera podido inocular el indicado virus, no generan responsabilidad patrimonial de la Administración sanitaria por no ser la lesión causada antijurídica".

De esta forma, en el ámbito de una situación extraordinaria y debido a la ausencia de certezas acerca de la misma es posible que no se pueda informar de forma adecuada, detallada o totalmente precisa o que esto último se realice con algún error fruto de la falta de conocimiento en dicho momento. ${ }^{7}$ En cuanto al COVID-19, debemos plantearnos si nos encontramos ante uno de estos casos. Pues bien, si atendemos a la alocución de apertura del Director General de la Organización Mundial de la Salud en la rueda de prensa sobre el COVID-19 celebrada el 11 de marzo de $2020,{ }^{8}$ en la que se declaró la pandemia, no parece inferirse que podía, de algún modo, preverse ni la existencia del virus ni su evolución. De hecho, en la fecha citada, el número de casos de COVID-19 fuera de China ya se había multiplicado por trece y el número de países afectados se había triplicado. Igualmente, el Real Decreto 463/2020, de 14 de marzo, por el que se declara el estado de alarma para la gestión de la situación de crisis sanitaria ocasionada por el COVID-19, pone de relieve la concurrencia de circunstancias extraordinarias que constituyen "sin duda, una crisis sanitaria sin precedentes y de enorme magnitud tanto por el muy elevado número de ciudadanos afectados como por el extraordinario riesgo para sus derechos".

Asimismo, la doctrina científica también apunta a que se trata de una enfermedad nueva e inédita. En este sentido, algunos autores destacan que estamos ante una "infección causada por un nuevo coronavirus" que ha dado lugar a la declaración de la Organización Mundial de la Salud sobre esta "emergencia de salud pública de interés internacional", considerada así de acuerdo con la sugerencia de un grupo de expertos y con los lineamientos del Reglamento Sanitario Internacional (RSI, 2005)" (RAMOS, 2020, p. 226). Por su parte, también se ha indicado que los pacientes presentaron "diagnósticos de neumonía de etiología no conocida" que representó "nueva amenaza” (KOURY GONZÁLEZ; HIRSCHHAUT, 2020, p. 3).

A pesar de ello, también es posible concluir en un sentido contrario. Máxime si atendemos a que en marzo de 2018 la Organización Mundial de la Salud ya incluyó la "enfermedad X" (disease X) en su listado de patógenos infecciosos. De hecho, se comenzó a referir la posibilidad de que se produjera una pandemia y se instó a los estados miembros a adoptar las medidas necesarias para estar preparados ante una posible emergencia causada por un patógeno desconocido. Además, tal y como apuntan muchas fuentes con el COVID-19, el origen de esta enfermedad se hizo residir en el contacto de las personas con los animales, ya que se indicó que se desarrollaría a través de un mecanismo de transmisión zoonótica. Igualmente, existen voces que aluden a la posibilidad de que el COVID-19 sea un virus creado por los humanos en los laboratorios.

Sea como fuere, entendemos que existen más evidencias para afirmar que el estado de la ciencia no permitió prever la naturaleza e impacto del COVID-19 y que, por tanto, no cabe exigir que los profesionales informaran correctamente sobre este extremo pues, sencillamente, no era posible. Ello no es óbice para señalar que, quizás, la gestión de esta crisis no ha sido la idónea y que, de haber tomado otras decisiones más acertadas, el impacto hubiera sido menor. No obstante, consideramos que este hecho no es imputable a los sanitarios. Obviamente, tras esta pandemia el conocimiento y la preparación debe ser mayor y, por

$5 \quad$ Vid., entre otras, las SSTS n. 9345/1996 Sala Tercera 17 abril 2001 (RJ 4215), n. 6972/1997 Sala Tercera 1 noviembre 2001 (RJ 10098 ), n. 7126/1997 Sala Tercera 22 noviembre 2001 (RJ 2002/5432), n. 5446/2005 Sala Tercera 8 octubre 2010 (RJ 7214 ).

6 Vid., entre otras, las SSTS n. 12/2002 Sala Tercera 29 noviembre 2002 (RJ 2003|283), n. 2911/2001 Sala Tercera 10 diciembre 2004 (RJ $2005 \backslash 473$ ), n. 172/2005 Sala Tercera 13 junio 2006 (RJ 3469).

7 Es posible plantear otros supuestos de responsabilidad en este ámbito. Por ejemplo, por integrar la inteligencia artificial para mejorar los tratamientos (DA GUIA SILVA; NOGAROLI, 2020, p. 293-300) o por infecciones producidas en el ámbito de la estructura sanitaria (GIOVA, 2020, p. 502-511). Bisponible en: https://www.who.int/es/dg/speeches/detail/who-director-general-s-opening-remarks-at-the-media-briefing-on-covid-19---11-march-2020 (fecha de última consulta 29.04.2020). 
tanto, de ocurrir otra en el futuro, el nivel de diligencia aumentará sin que quepa invocar ciertas cuestiones como eximentes de responsabilidad.

Todo lo anterior, nos lleva a concluir que, en principio, debido al estado de la ciencia, ciertas conductas no representan una fuente de responsabilidad. Así, por ejemplo, no cabría exigir esta última cuando el profesional no haya informado correctamente acerca de algún extremo relacionado con el coronavirus y sobre el que no disponía de datos suficientes. No obstante, es necesario establecer cuándo no será posible acudir a este razonamiento para excepcionar el consentimiento informado. En otras palabras, se trata de determinar el momento a partir del cual el estado de la ciencia permite comprender, al menos, las características y consecuencias fundamentales del COVID-19, pues, tras el mismo, no cabrá recurrir a la ausencia de conocimiento para fundamentar una exención de responsabilidad. Esta tarea es realmente compleja por varios motivos. Por un lado, porque es posible que los avances en la medicina resulten, posteriormente, revocados por otros estudios. No puede obviarse que estamos ante una ciencia no exacta que funciona a través del método heurístico, esto es, del ensayo y error. En este sentido, destaca de una forma muy acertada Rosenvald (2018, p. 377) que:

\begin{abstract}
Medicina, enfim, não é uma ciência tão exata como gostaríamos que fosse. As formas de abordagem e terapêutica diante do mesmo problema variam enormemente, dependendo do médico. Além do mais, conforme frisamos, os organismos humanos nem sempre respondem do mesmo modo. Quanto mais complexas forem as variáveis, mais difícil será prever, com exatidão, o que pode acontecer. Não raro, frente a um mesmo dilema técnico, médicos divergem frontalmente. Não é simples nem fácil, nesse contexto, solucionar judicialmente essas demandas, sobretudo se tivermos em conta o óbvio fato que o juiz não dispõe, pessoalmente, de formação profissional na área médica.
\end{abstract}

Las hipótesis que surgen están sometidas a verificación y esta última puede rechazar las certezas que se manejaban en un primer momento. De hecho, algo similar está ocurriendo con el COVID-19 tanto en la búsqueda de una vacuna como en su propio origen o consecuencias.

Por otro lado, porque no es sencillo determinar cuándo el estado de la ciencia es suficiente en un ámbito concreto. En este sentido, puede plantearse que esto último se produce cuando se dispone de una cura o tratamiento. Siguiendo este razonamiento, todavía no se habría producido tal circunstancia. Sin embargo, no queda claro que deba ser este el hecho determinante. Bien podría pensarse que basta con saber aquellos aspectos fundamentales de la enfermedad de que se trate. Asimismo, no puede obviarse que los virus evolucionan constantemente y que algunas vacunas se adaptan anualmente para hacer frente a las variaciones (como ocurre, por ejemplo, con la gripe).

Desde nuestra perspectiva, el nivel adecuado del estado de la ciencia sobre una patología se alcanza cuando se conoce su origen, sus causas y consecuencias principales y cuando, aun sin disponer de un tratamiento concreto totalmente eficaz, se está trabajando de forma avanzada en el mismo. En la actualidad, parece que no hemos logrado alcanzar tal estadio y que nos movemos en una fase intermedia, ya que a pesar de que se está preparando una vacuna, no se puede asegurar que la misma sea la correcta. Además, continúan apareciendo estudios que desmienten muchas de las hipótesis que se manejaban acerca de la procedencia misma del virus.

Sin embargo, no cabe acudir al razonamiento anterior para justificar todas aquellas intervenciones llevadas a cabo sin respetar la voluntad de los pacientes o sin cumplir ningún deber legal. El Tribunal Supremo, en jurisprudencia reiterada, ${ }^{9}$ ha destacado que:

La falta de información implica una mala praxis médica que no solo es relevante desde el punto de vista de la imputación sino que es además una consecuencia que la norma procura que no acontezca, para permitir que el paciente pueda ejercitar con cabal conocimiento (consciente, libre y completo) el derecho a la autonomía decisoria más conveniente a sus intereses, que tiene su fundamento en la dignidad de la persona que, con los derechos inviolables que le son inherentes, es fundamento

9 En este sentido, vid., entre otras, las SSTS n. 8065/1995 Sala Tercera 4 abril 2000 (RJ 3258), n. 1995/2007 19 noviembre 2007 (RJ 2008\18), n. 101/2011 4 marzo 2011 (RJ 2633), n. 323/2011 13 mayo 2011 (RJ 3279). 
del orden político y de la paz social (art. 10.1 CE) (...) La actuación decisoria pertenece al enfermo y afecta a su salud y como tal no es quien le informa sino él quien a través de la información que recibe, adopta la solución más favorable a sus intereses, incluso en aquellos supuestos en los que se actúa de forma necesaria sobre el enfermo para evitar ulteriores consecuencias. Lo contrario sería tanto como admitir que las enfermedades o intervenciones que tengan un único tratamiento, según el estado de la ciencia, no demandan "consentimiento informado".

De esta suerte, no es posible invocar el estado de la ciencia para prescindir de todas las obligaciones que prevé nuestra legislación actual. Imagínese, por ejemplo, que el médico entiende que, a pesar de la voluntad del usuario, lo más adecuado es aplicar una técnica concreta. Para poder realizar este ejercicio tendremos que buscar, en su caso, otros motivos que legitimen este extremo. Una conclusión diferente ampararía una actuación paternalista por parte de los profesionales, cuestión que se encuentra superada en la actualidad. A este respecto, conviene tener en cuenta, no obstante, que:

no deben confundirse las interferencias paternalistas con las perfeccionistas. En estas últimas, el Estado impone a las personas un determinado ideal acerca de lo que es bueno, correcto o virtuoso, con prescindencia del ideal individual. El paternalismo, en cambio, no impone un ideal de lo bueno, sino conductas o cursos de acción para que el individuo pueda realizar su propio plan de vida, que eligió en forma libre. (JUAN, 2020, p. 48).

La etapa de decisiones compartidas entre médico y paciente obliga a respetar, como norma general, la decisión de este último salvo que existan razones imperiosas que justifiquen una conducta diferente. Obviamente, ello no quiere decir que la rápida expansión del virus impida la aplicación de determinadas medidas previstas en nuestro ordenamiento, pero, en tal caso, tendremos que encontrar una base habilitadora. De hecho, esta toma de decisiones ha conllevado el recurso a mecanismos que, para parte de la doctrina, "han tenido un resultado que prudentemente se puede calificar de positivo en cuanto han ido paliando la extensión de la epidemia en nuestro país, preservando con ello la vida y la salud de las personas y, por ende, estos derechos que tan esenciales son al ser humano" (ALVENTOSA DEL RíO, 2020, p. 117).

En otro orden de cosas, conviene anudar una reflexión a todo lo anterior. Como resulta evidente, el avance de la ciencia y de la medicina depende, en gran medida, de las aportaciones que las autoridades destinen a tales fines. Son de sobra conocidas las peculiares circunstancias económicas de España, máxime desde la crisis financiera de 2008. Este hecho se agrava más, si cabe, por las devastadoras consecuencias del COVID-19 que ha paralizado la actividad de muchos países. Por lo tanto, los medios que se han puesto a disposición de los investigadores y profesionales en este ámbito han sido muy reducidos y no han permitido una mejor gestión.

\section{Principales conclusiones}

De todo lo visto hasta el momento, podemos extraer una serie de ideas. Por un lado, que los deberes que impone nuestra legislación en el ámbito del consentimiento informado obligan a que, con carácter general, los profesionales comuniquen al paciente todos aquellos relevantes de la intervención de que se trate y respeten la decisión de este último. En este sentido, encontramos dos facultades íntimamente relacionadas: información y consentimiento. Además, este derecho está vinculado a ciertos derechos constitucionales, lo cual obliga a extremar las precauciones en este sector. Desde nuestra perspectiva, la citada vinculación se produce, de forma más directa, con el derecho fundamental a la integridad física y moral (art. $15 \mathrm{CE}$ ). En esta misma línea, se pronunció el Tribunal Constitucional al señalar que, en suma, el consentimiento informado supone una expresión del libre desarrollo de la personalidad.

Sin embargo, lo cierto es que, por diversos motivos, no encontramos un reconocimiento real en la práctica del consentimiento informado, por lo que entendemos que la responsabilidad civil de este sector merece ser repensada a la luz de las actuales exigencias. Al realizar este ejercicio, consideramos que lo más adecuado es diferenciar entre dos clases de lex artis sanitaria. De un lado, la que podemos denominar tradicional referida a la adecuación de la operación que se realiza, esto es, a la correcta praxis. De otro lado, la nova lex artis que se ocupa de analizar si se han respetado los deberes impuestos por el consentimiento informado. 
Una vez señalado lo anterior, debemos destacar que no estamos ante un derecho absoluto. Muy al contrario, las especiales circunstancias que rodean al supuesto pueden provocar que, en el caso concreto, nos encontremos ante una excepción. En tales supuestos, o bien el médico o bien los familiares tendrán que actuar en representación y beneficio del usuario, sustituyendo su voluntad. Desde esta perspectiva, interesa que nos preguntemos acerca de la situación producida por el COVID-19 y sobre si la misma supone una habilitación suficiente para entender que debe limitarse el consentimiento informado.

En este sentido, este hecho se manifiesta en el ámbito del estado de la ciencia, ya que no es posible responsabilizar a un sujeto por aquellos actos cuando sus consecuencias eran desconocidas para el conjunto de la comunidad científica del momento. Sobre este particular, hemos indicado que el nivel de conocimiento no era (ni es) adecuado, por lo que ciertas actuaciones de los profesionales deben resultar exentas. Ello no quiere decir que se habilite para llevar a cabo una actividad con total inobservancia de las obligaciones legales, sino que no parece justo reprochar aquellas actuaciones que resulten no ser todo lo correctas que sería deseable (desde una perspectiva ex post) pero basadas en las certezas del momento. Algunos de los hechos que pueden encuadrarse en este razonamiento son, por ejemplo, la aplicación de tratamientos, medicamentos o la ejecución de intervenciones de urgencia sin obtener el consentimiento del paciente, así como la prestación de una información incorrecta. En este último caso, imagínese que se comunica al usuario que se encuentra afectado por el COVID-19 y, en realidad, no lo está o, al contrario, esto es, que se le indique que no tiene ningún problema cuando, sin embargo, tiene el virus en su organismo. De hecho, en este último supuesto las consecuencias pueden afectar a terceras personas en la medida en que, al no tomar las precauciones y las medidas de seguridad necesarias como consecuencia de la errónea información, contagie a familiares $o$ a conocidos.

\section{Referencias}

ALVENTOSA DEL RÍO, Josefina. Salud y derecho en tiempos del COVID-19. AJI, Madrid, n. 12 bis, p. 108-117, mayo 2020.

BARCELÓ DOMÉNECH, Javier. Consentimiento informado y responsabilidad médica. AJI, Madrid, n. 8 , p. 279-296, feb. 2018.

BARCELÓ DOMÉNECH, Javier. Régimen jurídico de las vacunas en España: reflexiones ante la situación creada por el coronavirus. AJI, Madrid, n. 12 bis, p. 118-125, mayo 2020.

BLANCO PÉREZ-RUBIO, Lourdes. El consentimiento informado como elemento esencial de la lex artis. Aranzadi civil-mercantil. Revista doctrinal, Cizur Menor, Navarra, v. 2, n. 2, p. 89-122, mayo 2014.

BLAS ORBÁN, Carmen. Contagio transfusional de VHC: reflexiones sobre la previsibilidad del daño. DS, España, v. 16, n. 2, p. 181-182, 2008.

DA GUIA SILVA, Rodrigo; NOGAROLI, Rafaella. Utilização da inteligência artificial na análise diagnóstica da COVID-19: benefícios, riscos e repercussões sobre a responsabilidade civil do médico. En: MONTEIRO FILHO, Carlos Edison do Rêgo; ROSENVALD, Nelson; DENSA, Roberta (coord.). Coronavírus e responsabilidade civil: impactos contratuais e extracontratuais. Indaiatuba, SP: Foco, 2020. p. 293-300.

DE LAS HERAS GARCÍA, Manuel Ángel. Lex Artis, Onus Probandi y responsabilidad médica. Revista jurídica de la Región de Murcia, Murcia, n. 36, p. 17-19, 2005.

DÍAZ MARTíNEZ, Ana. El consentimiento informado como garantía del derecho fundamental a la integridad física y moral: comentario a la STC 37/2011 de 28 de marzo (RTC 2011,37). Aranzadi CivilMercantil. Revista Doctrinal, Cizur Menor, Navarra, v.1, n. 5, p. 25-35, dec. 2011.

GIOVA, Stefania. Infezione da COVID-19 e responsabilità della struttura sanitaria. AJI, Madrid, n. 12 bis, p. 502-511, mayo 2020.

GÓMEZ ABEJA, Laura. Consentimiento informado y derechos fundamentales. Revista Europea de Derechos Fundamentales, Granada, n. 18, p. 275-306, 2011. 
GUTIÉRREZ SANTIAGO, Pilar. La constitucionalización del Derecho Civil. Estudios de Derecho, Medellín, Antioquia, v. 68, n. 151, p. 51-86, 2011.

JUAN, Gabriel. Coronavirus y paternalismo (in)justificado. AJI, Madrid, n. 12 bis, p. 42-51, mayo 2020.

KOURY GONZÁLEZ, Juan Miguel; HIRSCHHAUT, Miguel. Reseña histórica del COVID-19. ¿Cómo y por qué llegamos a esta pandemia?. Acta odontológica venezolana, Caracas, v. 58, n. extra 1, p. 3-4, 2020.

MUGA MUÑOZ, José Luis. La responsabilidad patrimonial de las administraciones publicas por el contagio de sida. Revista de Administración Pública, Madrid, n. 136, p. 277-308, 1995.

ORTIZ FERNÁNDEZ, Manuel. El consentimiento informado en el ámbito sanitario: la lex artis y los derechos fundamentales. En: LOUREIRO, João Carlos; DIAS PEREIRA, André; BARBOSA, Carla. Cadernos da Lex Medicinae (Saúde, novas tecnologias e responsabilidades). Coimbra: Instituto Jurídico, Faculdade de Direito da Universidade de Coimbra, 2019. v. 2, n. 4, p. 369-380.

ORTIZ FERNÁNDEZ, Manuel. La responsabilidad civil en el ámbito sanitario derivada del consentimiento informado. Actualidad Jurídica Iberoamericana, Madrid, n. 10 bis, p. 548-565, jun. 2019.

ORTIZ FERNÁNDEZ, Manuel. Algunos apuntes sobre la responsabilidad civil sanitaria ante la situación generada por el COVID-19. Revista IBERC: Edição Especial "Coronavírus e Responsabilidade Civil", Rio de Janeiro, v. 3, n. 2, p. 289-304, 10 ago. 2020. Disponível em: https://revistaiberc.responsabilidadecivil. org/iberc/article/view/126/98. Acesso em: 7 set. 2020.

RAMOS, Celso. Covid-19: la nueva enfermedad causada por un coronavirus. Salud pública de México, Cuernavaca, v. 62, n. 2, p. 225-227, 2020.

RÊGO MONTEIRO FILHO, Carlos Edison do. Coronavírus e força maior: configuração e limites. En: RÊGO MONTEIRO FILHO, Carlos Edison do; ROSENVALD, Nelson; DENSA, Roberta (coord.). Coronavírus e responsabilidade civil: impactos contratuais e extracontratuais. Indaiatuba, SP: Foco, 2020. p. 19-36.

ROSENVALD, Nelson. Responsabilidade civil na área médica. AJI, Madrid, n. 8, p. 373-420, 2018.

ROSENVALD, Nelson. O direito como experiência. Dos "coronation cases" aos "coronavírus cases". AJI, Madrid, n. 12 bis, p. 250-257, mayo 2020.

ROVIRA VIÑAS, Antonio. Dignidad, autonomía, libertad y consentimiento informado. Revista de las Cortes Generales, Madrid, n. 67, p. 7-54, abr. 2006.

ROVIRA VIÑAS, Antonio. Autonomía personal y tratamiento médico: una aproximación constitucional al consentimiento informado. Navarra: Aranzadi, 2007.

SÁNCHEZ GÓMEZ, Amelia. La información al paciente y el consentimiento informado en el Derecho Español: referencia legal y jurisprudencial. La praxis médica. Aranzadi civil-mercantil. Revista doctrinal, Cizur Menor, Navarra, v. 2, n. 8, p. 97-117, dec. 2014.

SARDINERO GARCÍA, Carlos. Responsabilidad administrativa, civil y penal por falta de información en el ámbito clínico: criterios indemnizatorios. Valencia: Tirant lo Blanch, 2016.

Recebido em: 22/09/2020

Aprovado em: 07/12/2020 